\title{
CARACTERIZAÇÃO DO MATERIAL ORIGINÁRIO DOS SOLOS DE PARTE DA QUADRÍCULA DE IBITIARA COMO SUBSÍDIO PARA ESTUDOS GEOQUÍMICOS
}

\author{
JOAQUIM JÚLIO DE OLIVEIRA*, JAMES H. GALBRAITH** e GASTON R. \\ SIEFFERMANN***
}

\begin{abstract}
The principal types of source material for soils in the western part of the Ibitiara quadrangle were determined with the objective of characterizing surface formations as an aid in geochemical prospecting.

Three types of source material were differentiated in the depression of Paramirim River: aloctonous (transported), autoctonous (residual) and alluvial-colluvial material. An analysis of variance and comparison of means of data obtained from soils developed over aloctonous and autoctonous material showed significant differences between the two types for most of the studied parameters. Soils developed over aloctonous material display: a stone line over ferruginous duricrust or altered basement; weak, friable structure; a clayey-sand texture which varies to sandy-clay with depth; weak ion exchange capacity; $\mathrm{pH}$ near 5.0; predominantly kaolinitic clays; and low trace element content. Soils developed over autoctonous material are characterized by: high base saturation; block structure; $\mathrm{pH}$ above 6.0 ; high ion exchange capacity; predominantly montmorillonite clays; and high trace element content. Within the two types no significant difference was found in most of the parameters with depth. Soils derived from alluvium-colluvium material show prismatic structure in the $\mathrm{B}$ horizon; $\mathrm{pH}$ greater than 6.0 ; high base saturation; high ion exchange capacity; and $\mathrm{Na}$ and $\mathrm{Ca}$ rich montmorillonite clays.

Regional geochemical prospecting should be carried out with active stream sediment samples which will probably be a mixture of the different soil types and should register anomalies. Geophysical techniques should be used in areas where soils derived from aloctonous material is thick. Detailed geochemical prospecting may be employed with surface soil samples, but where the soils are developed from aloctonous material the anomalies will be epigenetic.
\end{abstract}

INTRODUÇÃO Este trabalho é o resultado de estudos realizados no quadro do convênio celebrado entre a UFBa/BNDE/FUNTEG ${ }^{1}$. Durante a fase inicial de nossas pesquisas, foram identificados os principais tipos de material originário dos solos da parte ocidental da quadrícula de Ibitiara. Os estudos foram orientados visando a locação de uma série de seqüências ou toposseqüências a fim de se reconhecerem os tipos de solos da região. Em seguida, considerando-se os recursos materiais disponíveis, sobretudo a documentação cartográfica, verificou-se que a contribuição mais efetiva para a prospecção geoquímica regional seria aquela que permitisse estabelecer uma metodología para a caracterização morfológica (descrição de perfis) e físico-química das formações superficiais a partir das quais os solos evoluem.

Analisou-se uma série de quarenta e oito perfis, dos quais dez foram selecionados para a realização deste trabalho.

As hipóteses estabelecidas a partir das descrições morfológicas dos perfis sugeriam que havid uma diferenciação significativa entre os solos desenvolvidos sobre material originário

*Instituto de Geociências da Universidade Federal da Bahia

**Pesquisador visitante, Instituto de Geociências da Universidade Federal da Bahia

*** Chefe da Missão ORSTOM na Bahia

${ }^{1}$ A coordenação geral do convênio estava a cargo da professora Adelaide Mussi Santos, chefe do Departamento 01 - Instituto de Geociências da UFBa 
alóctone e os solos desenvolvidos sobre material originário autóctone, seja o produto da alteração do substrato in situ.

A caracterização morfológica, efetuada no terreno foi estabelecida baseando-se em métodos pedológicos e geomorfológicos. As análises e determinações fisico-químicas do material amostrado foram realizadas em laboratório e os resultados tratados estatisticamente.

Síntese das características do quadro regional LUCALIZAÇÃO DA ÁREA ESTUDADA A quadrícula de Ibitiara (folha topográfica na escala de 1:100000) está situada na parte central da Bahia, estendendo-se desde $12^{\circ} 30^{\prime}$ a $13^{\circ} 00^{\prime}$ de latitude sul e $42^{\circ} 00^{\prime}$ a $42^{\circ} 30^{\prime}$ de longitude oeste (veja Fig. 1). A região faz parte de extenso conjunto, a Chapada Diamantina, que sempre despertou um grande interesse do ponto de vista geológico, pela incidência de ocorrências minerais, sendo, por conseguinte, objeto de vários estudos de reconhecimento (Kegel, 1959; Campbell e da Costa, 1965; Schobbenhaus, 1967). Os estudos geológicos mais recentes e detalhados da referida região foram realizados pela Divisão de Geologia da Sudene visando mapear e localizar as ocorrências minerais, sobretudo as ocorrências de $\mathrm{Cu}, \mathrm{Pb}, \mathrm{Ba}$ etc. Determinadas áreas foram objeto de estudos durante os estágios dos estudantes do curso de Geologia da Universidade Federal da Bahia.

ASPECTOS GEOLÓGICOS A região ocidental da Chapada Diamantina caracteriza-se por apresentar aspectos litológicos variados. Schobbenhaus (op. cit.) destacou três unidades litológicas, às quais acrescentamos uma quarta unidade, referente aos sedimentos inconsolidados e carapaças ferruginosas de idade quaternária. As unidades são dadas a seguir.

Unidade I. Nesta unidade estão agrupadas as rochas do complexo granito-gnáissico-migmatítico atribuídas ao Arqueano. Essas rochas afloram na parte ocidental da quadrícula, na depressão do Rio Paramirim, e, igualmente, no fundo dos vales, profundamente encaixados, localizados no centro da área e cuja orientação geral é norte-sul.

Unidade II. As rochas efusivas ácidas compõem esta unidade, que os geólogos atribuíram ao Pré-Cambriano Médio. Os riolitos, riodacitos e dacitos ocorrem na área central da quadrícula, formando uma faixa de aproximadamente $15 \mathrm{~km}$ de largura, disposta no sentido norte-sul. Essas rochas, localmente, aparecem metamorfoseadas e transformadas, de modo completo, em quartzo-sericita-xistos.

Unidade III. Esta unidade está representada por metassedimentos atribuídos ao Pré-Cambriano Superior. O conjunto sedimentar sofreu os efeitos de um metamorfismo de epizona e como resultado observa-se uma seqüência de quartzitos, conglomerados quartzíticos, filitos, calcários cristalinos e arenitos fracamente metamorfoseados.

As rochas que compõem essas três unidades foram afetadas por uma série de falhas e fraturas, as quais foram preenchidas por quartzo de origem hidrotermal ou corpos de diabásio. As ocorrências de diques de diabásio são freqüentes nos arredores de Ibitiara e da localidade de Novo Horizonte, ao longo dos vales.

Unidade IV. Nesta unidade incluímos os sedimentos inconsolidados e as carapaças ferruginosas. O conjunto pode ser diferenciado em: (a) formações superficiais de natureza areno-argilosa e argilo-arenosa, contendo, muitas vezes, níveis constituídos de acumulações de seixos, blocos de quartzito, arenito e fragmentos de quartzo. Ao longo dos principais entalhes ou rupturas de declive, é comum o afloramento de carapaças ou couraças ferrugi- 


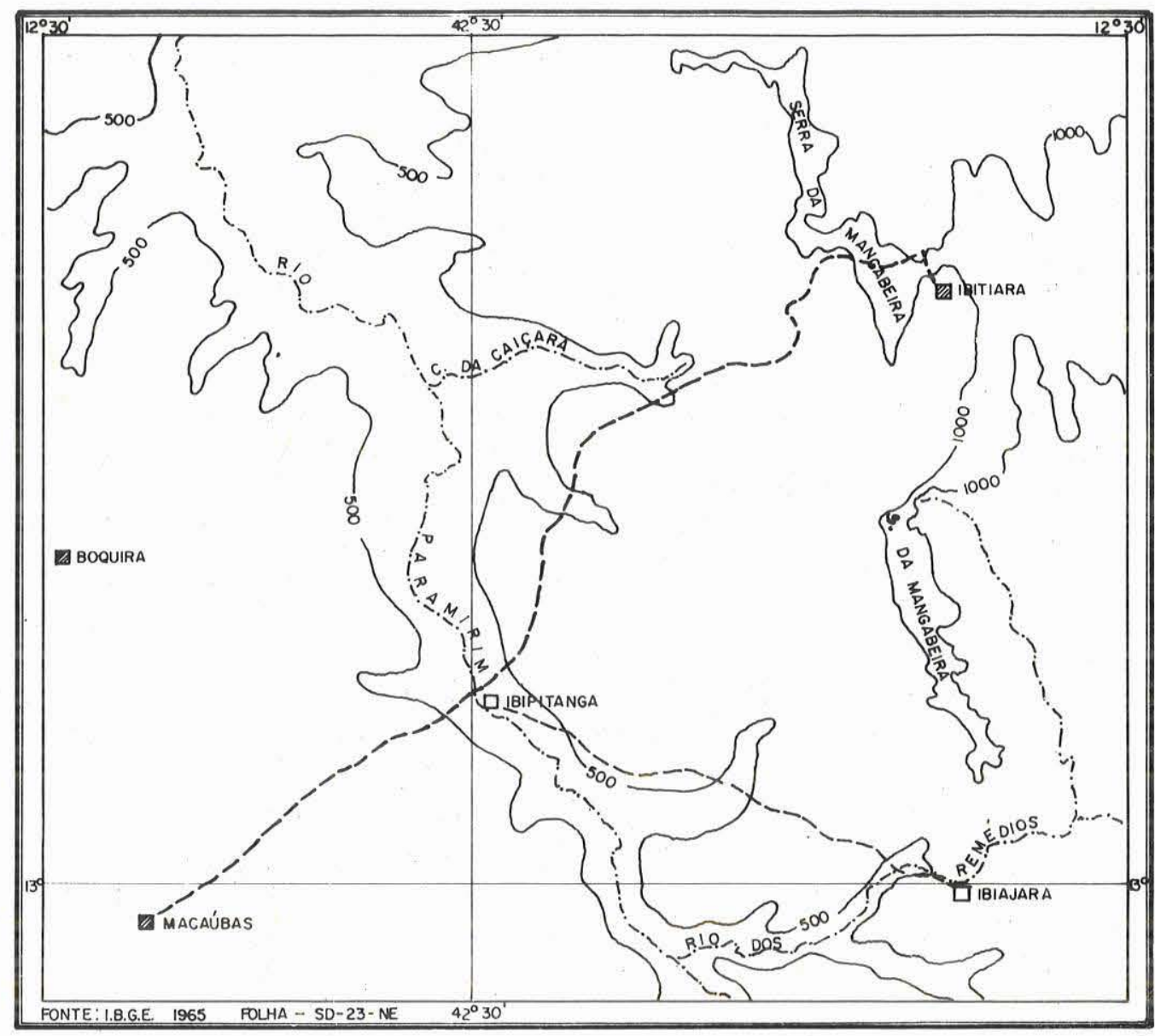

LEGENDA
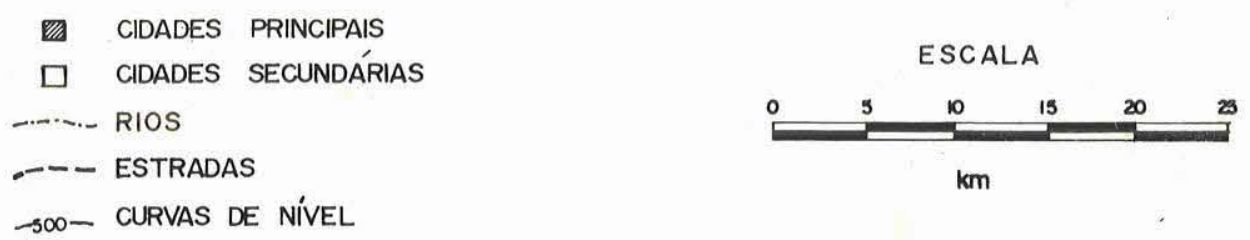

Figura 1 - Região estudada: depressão do Rio Paramirim

nosas conglomeráticas; (b) formações alúvio-coluviais, apresentando textura areno-argilosa, estratificadas ou não-estratificadas, cuja ocorrência está associada ao transporte fluvial e ao escoamento difuso nas encostas e interflúvios; e (c) formações superficiais provenientes da alteração in situ dos diferentes substratos. Estas são essencialmente argilosas e encontram-se ao longo dos vales em encostas onde a erosão é mais intensa.

FEIÇÕES MORFOLÓGICAS A característica principal do relevo da quadrícula de Ibitiara é dada pela oposição entre o planalto montanhoso e a planície drenada pelo Rio Paramirim e seus afluentes. O planalto montanhoso faz parte de um vasto conjunto sedi- 
mentar metamórfico cuja evolução está ligada a problemas estruturais e à ação de sucessivos ciclos morfoclimáticos a que foi submetido desde o Terciário (Oliveira, 1968). As formas dominantes estão representadas por uma série de serras alongadas e dispostas paralelamente, orientadas norte-sul, separadas por vales profundamente entalhados.

A planície do Rio Paramirim pode ser considerada como uma zona de desnudação pré-quaternária recoberta por sedimentos pleistocênicos e holocênicos provenientes da alteração e erosão do planalto montanhoso (Maack, 1963). Os traços morfológicos mais importantes na planície são representados pelos largos interflúvios entalhados por uma rede de drenagem constituída por riachos temporários, possuindo como nível de base o Rio Paramirim. A maioria desses riachos temporários tem suas nascentes na encosta ocidental da Serra da Mangabeira. Os interflúvios funcionam atualmente como glacis de erosão e a passagem aos terraços aluviais faz-se através de uma superfície inclinada, rejuvenescida e, muitas vezes, modelada no próprio produto da alteração do substrato subjacente. Localmente, dessa superficie geral, situada entre 500 e 750 metros, emergem relevos residuais, constituindo verdadeiros Inselberge. Várias depressões circulares podem ser observadas na planície do Rio Paramirim. A origem dessas depressões está relacionada, provavelmente à alteração diferencial do substrato rochoso.

As feições morfológicas da região de Ibitiara podem ser atribuídas ao resultado da ação de processos morfoclimáticos de regiões tipicamente semi-áridas, colocando em evidência a estrutura litológica através de forte erosão diferencial.

ASPECTOS CLIMÁTICOS E VEGETAÇÃO O clima da região de Ibitiara é caracterizado por uma pluviosidade média anual da ordem de $600 \mathrm{~mm}$, conforme os dados considerados para o período 1934-60, (Andrea, 1963). A média anual do número de dias de chuva é de 36 , o que supõe um regime de precipitações concentradas em apenas cinco meses, nitidamente torrencial e irregular. As chuvas são registradas nos meses de novembro a março, quando as temperaturas são as mais elevadas, ocasionando uma forte evaporação.

Do ponto de vista térmico, a média das temperaturas máximas e a média das temperaturas mínimas registradas para aquele período oscilam entre $30^{\circ} \mathrm{C}$ e $18^{\circ} \mathrm{C}$, respectivamente (Andrea, op. cit.).

A região está submetida à ação de um clima quente e seco, mesmo semi-árido, que, na classificação de Koppen, corresponde ao clima do tipo BSh.

A vegetação da área é do tipo xerófilo. Observam-se, no conjunto, variações locais. Destacam-se as associações de angico (Piptadenia rigida, Bth e Piptadenia colubrina, Bth) e jurema (Pithecolobrium diversiflorum). As cactáceas constituem elemento importante na paisagem vegetal da região.

Material originário dos solos da depressão do Rio Paramirim CARACTERIZAÇÃO MORFOLÓGICA O estudo dos quarenta e oito perfis de solos localizados em diferentes posições topográficas permitiu-nos concluir que ocorria sempre o mesmo tipo de material originário em superfícies de mesmo nível topográfico. A análise morfológica e a descrição de todos esses perfis evidenciou, inicialmente, a ocorrência de três tipos de materiais originários:

- material originário de natureza alóctone,

- material originário de natureza autóctone e

- material originário de natureza alúvio/coluvial (alóctone). 
Observa-se, como característica essencial, permitindo diferenciar os dois primeiros tipos de material, um lençol de seixos e blocos situado na base dos perfis constituídos de material alóctone. Os lençóis de seixos e blocos jazem em discordância sobre o produto de alteração do substrato subjacente ou diretamente sobre ele. A espessura dessas camadas de seixos e blocos é variável $(20$ a $50 \mathrm{~cm})$ e predominam os seixos de quartzito, arenito e quartzo, alterados diferencialmente.

Os perfis de solos sobre material originário autóctone apresenta, ocasionalmente, uma linha de seixos na base do horizonte $A$ e em profundidades variaveis entre 30 e $50 \mathrm{~cm}$.

Os solos desenvolvidos a partir do material alóctone apresentam freqüentemente horizonte $A$ areno-argiloso com um gradativo aumento do teor de argila nos primeiros $50 \mathrm{~cm}$, enquanto os solos desenvolvidos a partir de material autóctone apresentam teor de argila elevado desde a superfície. Nestes solos, o horizonte $A$ pode ser constituído de material proveniente do retrabalhamento das formaçóes superficiais alóctones localizadas nas partes planas, os interflúvios, ou simplesmente do próprio material produto da alteração do substrato subjacente.

A estrutura pode ser tomada como parâmetro indicador da natureza do material. Os solos desenvolvidos a partir de material alóctone apresentam estrutura fraca e muito friável, enquanto a estrutura dos solos desenvolvidos a partir do material autóctone é sempre forte a muito forte, forma blocos angulares a subangulares, muito consistentes quando secos, indicando a presença de minerais argilosos da família da montmorilonita. Mineralogicamente, nestes solos, o teor em minerais alteráveis é apreciável, especialmente a muscovita e os feldspatos, o que não ocorre nos solos evoluídos sobre material alóctone. Estes parecem tratar-se de material em estado último de alteração (Jackson, 1953) e ferralitizados.

CARACTERIZAÇÃO FISICO-QUYMICA As amostras coletadas foram tratadas e submetidas a análises para sua caracterização físico-química. As análises e determinações efetuadas foram: granulometria, $\mathrm{pH}$, bases trocáveis, capacidade total de troca cationica, soma das bases trocáveis, carbono orgânico, ferro total, difractometria de raios $\mathrm{X}$ na fração inferior a 44 mícrons, 2 mícrons e teor de elementos-traços por absorção atômica (Cu, $\mathrm{Pb}, \mathrm{Zn}, \mathrm{Co}, \mathrm{Cr}, \mathrm{Mn})$. Não entraremos em detalhes para a apresentação dos métodos utilizados para tais determinações, uma vez que, em Pedologia e Geoquímica, são métodos consagrados, conhecidos na maioria dos laboratórios.

\section{APRESENTACÃ̃O DE DOIS PERFIS DE SOLOS TÍPICOS DA REGIÃO Perfil $1 \mathrm{~B}$ n. ${ }^{\circ} 6$}

Generalidades

Localização: dista $400 \mathrm{~m}$ da ponte sobre o Rio Remédios, margem esquerda da estrada Ibiajara-Ibipitanga (veja Fig. 2).

Altitude: $\quad 610 \mathrm{~m}$.

Relevo: suave-ondulado, encosta do vale do Rio Remédios; inclinação entre 10 e $15 \%$.

Vegetação: capoeira rala; caatinga hiperxerófila.

Superficie: blocos de arenito, quartzito arredondados e fragmentos de quartzo heterométricos dispersos.

Erosão: laminar moderada a forte.

Material

originário: alteração do substrato regional (gnaisse).

Glassificação: podzólico vermelho-amarelo equivalente eutrófico, textura argilosa, A fraco, fase caatinga hiperxerbfila, relevo suave ondulado. 

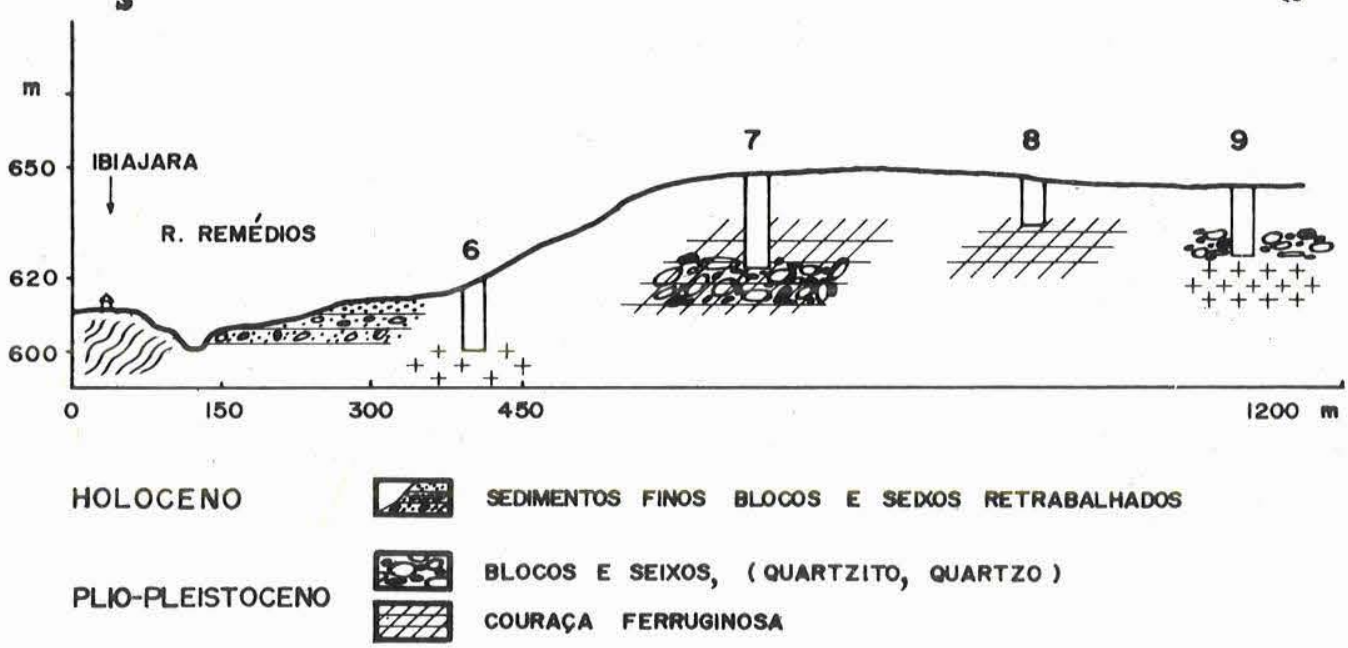

PRÉ-CAMBRIANO 屆萧 XISTOS E GNAISSES

Figura 2 - Corte esquemático e localização da seqüência de perfis (6, 7, 8 e 9) em Ibiajara

Descrif̧ão

Horizontes :

Al -0 a $15 \mathrm{~cm}$

Argilo-siltoso; 5YR 4/6 (terra seca), 5YR 3/6 (terra úmida). Estrutura em blocos subangulares médios, subestrutura poliédrica fina; porosidade média a boa; presença de concreções de $\mathrm{Fe}$ e $\mathrm{Mn}$ inferiores a $2 \mathrm{~mm}$ de diâmetro; fragmentos de quartzo e seixos de quartzito e arenito de 1 a $20 \mathrm{~cm}$ de diâmetro. Raízes traçantes numerosas e limite inferior nítido e ondulado.

IIB21 - 15 a $70 \mathrm{~cm}$

Argiloso; 5YR 4/8 (terra seca), 5YR 5/8 (terra úmida). Estrutura em prismas, agregados de 15 a $40 \mathrm{~cm}$, subestrutura poliédrica a elementos médios de 2 a $5 \mathrm{~cm}$. Algumas faces de deslizamento (slikensides); fendas de retração de $1 \mathrm{~cm}$; presença de nódulos e concreções de Fe e Mn inferiores a $3 \mathrm{~mm}$ de diâmetro; raros fragmentos de quartzo na base. Raízes raras; limite inferior gradual e ligeiramente ondulado.

IIB22 - 70 a $95 \mathrm{~cm}$

Argiloso; 7,5YR 6/8 (terra seca), 10YR 4/6 (terra úmida); manchas de hidromorfia 7,5YR 5/6. Estrutura em blocos, subestrutura subangular, agregados de 1 a $2 \mathrm{~cm}$; fraca porosidade; algumas faces de deslizamento (slikensides) pouco nítidas; revestimentos; presença de nódulos de Fe e Mn inferiores a $2 \mathrm{~mm}$. Manchas de hidromorfia ao longo das finas e raras raízes. Limite inferior gradual.

IIC - 95 a $250 \mathrm{~cm}$

Rocha alterada muito friável; 2 Y $7 / 6$ (terra seca), 2Y 6/4 (terra úmida). Desde a profundidade de $95 \mathrm{~cm}$ até $150 \mathrm{~cm}$ manchas de cor ocre a ocre escuro; estrutura ligeiramente prismática; presença de alguns nódulos de $\mathrm{Mn}$; nódulos de $\mathrm{CaCO}_{3}$ entre 300 e $250 \mathrm{~cm}$ ao longo das fissuras. Raras raízes e limite inferior gradual e ondulado.

IIR $-250 \mathrm{~cm}$

Rocha semi-alterada a estrutura conservada. 2 Y $7 / 4$ (seca), 2Y 5/4 a $6 / 4$ (úmida). Gnaisse. 
Tabela I - Resultados analíticos obtidos para o perfil 1B n. ${ }^{\circ} 6$

\begin{tabular}{|c|c|c|c|c|c|c|c|}
\hline \multicolumn{2}{|c|}{ Número da amostra } & 61 & 62 & 63 & 64 & 65 & 66 \\
\hline \multicolumn{2}{|c|}{ Profundidade $(\mathrm{em} \mathrm{cm})$} & $0-10$ & $20-30$ & $40-50$ & $75-85$ & $120-130$ & $200-220$ \\
\hline \multirow{2}{*}{$\mathrm{pH}$} & $\mathrm{em} \mathrm{H}_{2} \mathrm{O}$ & 6,4 & 5,9 & 5,7 & 6,3 & 6,2 & 8,0 \\
\hline & em KCI & 5,0 & 3,8 & 3,6 & 3,9 & 3,4 & 5,6 \\
\hline \multirow{6}{*}{$\begin{array}{l}\text { Granu- } \\
\text { lometria } \\
\% \text { das } \\
\text { frações }\end{array}$} & fração $>2 \mathrm{~mm}$ & 10,0 & 15,0 & 10,0 & 4,0 & 3.0 & - \\
\hline & areia grossa & 11,0 & 7,0 & 6,0 & 7,0 & 9,0 & 8,0 \\
\hline & areia fina & 14,0 & 10,0 & 11,0 & 12,0 & 26,0 & 18,0 \\
\hline & silte grosso & 11,0 & 10,0 & 7,0 & 13,0 & 8,0 & 28,0 \\
\hline & silte fino & 17,0 & 18,0 & 18,0 & 24,0 & 35,0 & 16,0 \\
\hline & argila & 40,0 & 41,0 & 48,0 & 38,0 & 20,0 & 30,0 \\
\hline \multirow{5}{*}{$\begin{array}{l}\text { Bases } \\
\text { trocáveis } \\
\text { meq } / 100 \\
\mathrm{~g} \text { de solo }\end{array}$} & $\mathrm{Ca}$ & 16,0 & 15,0 & 17,0 & 21,0 & 23,0 & 21,0 \\
\hline & $\mathrm{Mg}$ & 8,0 & 11,0 & 16,0 & 22,0 & 23,0 & 20,0 \\
\hline & $\mathrm{K}$ & 0,3 & 0,1 & 0,1 & 0,1 & 0,1 & 0,1 \\
\hline & $\mathrm{Na}$ & 0,2 & 0,6 & 1,4 & 2,5 & 3,0 & 2,6 \\
\hline & Soma (S) & 24,5 & 26,7 & 34,5 & 45,6 & 49,1 & 43,7 \\
\hline \multicolumn{2}{|c|}{ Capacidade total de troca $(\mathrm{T})$} & 28,9 & 32,5 & 35,8 & 40,7 & 38,4 & - \\
\hline \multicolumn{2}{|c|}{$\mathrm{V}(\mathrm{S} / \mathrm{T} \times 100)$} & 84,0 & 83,0 & 96,0 & - & - & - \\
\hline \multicolumn{2}{|c|}{ Carbono orgânico $(\%)$} & 1,3 & 0,7 & 0,1 & - & - & - \\
\hline \multicolumn{2}{|c|}{ Umidade $(\%)$} & 5,8 & 10,0 & 10,0 & 12,0 & 9,0 & 8,6 \\
\hline
\end{tabular}

Perfil $1 \mathrm{~B}$ n. 9

\section{Generalidades}

Localização: dista $1200 \mathrm{~m}$ da ponte sobre o Rio Remédios, margem esquerda da estrada Ibiajara-Ibipitanga (veja Fig. 2).

Altitude: $625 \mathrm{~m}$.

Relevo: plano; inclinação para noroeste em torno de $5 \%$.

Vegetação: capoeira rala; presença de áreas desnudadas. Caatinga hiperxerófila.

Superfície: plana, presença de areia grossa constituída de quartzo e feldspato e raros seixos de quartzito.

Erosão: laminar moderada a forte.

Material

originário: areno-argiloso contendo stone-line jazendo sobre alteração incipiente de substrato gnáissico.

Classificação: laterita hidromórfica $\operatorname{com} B$ textural.

\section{Descrição}

Horizontes :

A11 - 0 a $10 \mathrm{~cm}$

Arenoso; 7,5YR 7/3 (terra seca), 10YR 6/4 (terra úmida); estrutura em blocos subangulares, agregados de 1 a $2 \mathrm{~cm}$ frágeis. Manchas de hidromorfia pouco nítidas, 5YR 7/6; porosidade boa. Algumas raízes finas e limite inferior gradual. 
$\mathrm{A} 12$ - 10 a $25 \mathrm{~cm}$

Arenoso; 7,5YR 7/2 (terra seca), 10YR 6/4 (terra umida), aspecto maciço, estrutura em blocos subangulares muito friável. Raros fragmentos de quartzo; nódulos de Fe de cor ocre; porosidade boa; presença de manchas de hidromorfia difusas. Raras raízes e limite inferior pouco nítido e difuso.

B21 - 25 a $65 \mathrm{~cm}$

Arenoso a areno-argiloso; consistente a muito consistente, 10YR 6/2 (terra seca), 10YR 6/4 (terra úmida); porosidade média a boa. Numerosos fragmentos de quartzo de diâmetro inferior a $5 \mathrm{~cm}$; raros nódulos e concreções ferruginosas de 0,5 a $1 \mathrm{~cm}$ de cor violácea a bruno ocre; manchas de hidromorfia a partir de $45 \mathrm{~cm}$ de profundidade. Limite inferior nítido.

B22 - 65 a $130 \mathrm{~cm}$

Areno-argiloso a argilo-arenoso; 5YR 5/6 a 5YR 4/6 (terra seca), 10YR 7/6 (terra úmida); manchas de hidromorfia ocres dominantes. Estrutura em blocos subangulares, pouco nítida, moderada, consistente a muito consistente; porosidade boa; a $90 \mathrm{~cm}$ de profundidade presença de stone-line constituído de seixos e blocos de quartzito e quartzo. Raras raízes; alguns nódulos ferruginosos e/ou manganosos de $1 \mathrm{~cm}$ de diametro. Transição abrupta e ondulada.

IIC - 130 a $150 \mathrm{~cm}$ Argiloso a argilo-arenoso; manchas de hidromorfia; 10YR 7/6 (terra seca), 10YR 5/6 (terra úmida); estrutura pouco nítida em blocos subangulares muito duros; fraca porosidade. Limite inferior irregular e ondulado.

IIR $-150 \mathrm{~cm}$

Rocha semi-alterada a estrutura conservada (gnaisse).

Tabela II - Resultados analíticos obtidos para o perfil $1 \mathrm{~B} \mathrm{n} .^{\circ} 9$

\begin{tabular}{|c|c|c|c|c|c|c|c|}
\hline \multicolumn{2}{|c|}{ Número da amostra } & 91 & 92 & 93 & 94 & 95 & 96 \\
\hline \multicolumn{2}{|c|}{ Profundidade $(\mathrm{em} \mathrm{cm})$} & $0-10$ & $10-20$ & $40-50$ & $80-90$ & $110-120$ & $130-140$ \\
\hline \multirow{2}{*}{$\mathrm{pH}$} & em $\mathrm{H}_{2} \mathrm{O}$ & 4,5 & 4,5 & 4,7 & 5,5 & 5,7 & 6,4 \\
\hline & em KCI & 4,0 & 4,0 & 4,1 & 4,4 & 4,4 & 4,1 \\
\hline \multirow{6}{*}{$\begin{array}{l}\text { Granu- } \\
\text { lometria } \\
\% \text { das } \\
\text { frações }\end{array}$} & fração $>2 \mathrm{~mm}$ & 13,0 & 18,0 & 28,0 & 38,0 & 43,0 & 35,0 \\
\hline & areia grossa & 40,0 & 36,0 & 29,0 & 20,0 & 22,0 & 22,0 \\
\hline & areia fina & 38,0 & 38,0 & 26,0 & 18,0 & 24,0 & 21,0 \\
\hline & silte grosso & 6,0 & 8,0 & 13,0 & 14,0 & 14,0 & 13,0 \\
\hline & silte fino & 3,0 & 3,0 & 6,0 & 8,0 & 8,0 & 9,0 \\
\hline & argila & 12,0 & 16,0 & 25,0 & 39,0 & 30,0 & 30,0 \\
\hline \multirow{5}{*}{$\begin{array}{l}\text { Bases } \\
\text { trocáveis } \\
\text { meq/100 } \\
\mathrm{g} \text { de solo }\end{array}$} & $\mathrm{Ca}$ & 0,5 & 0,3 & 0,4 & 0,4 & 1,1 & 1,1 \\
\hline & $\mathrm{Mg}$ & 0,2 & 0,1 & 2,4 & 3,1 & 0,9 & 2,5 \\
\hline & $\mathrm{K}$ & 0,1 & 0,1 & 0,2 & 0,4 & 0,4 & 0,4 \\
\hline & $\mathrm{Na}$ & 0,02 & 0,02 & 0,02 & 0,1 & 0,2 & 2,1 \\
\hline & Soma $(S)$ & 0,8 & 0,5 & 2,9 & 4,0 & 2,6 & 6,1 \\
\hline \multicolumn{2}{|c|}{ Capacidade total de troca $(\mathrm{T})$} & 3,7 & 3,3 & 3,2 & 7,3 & 5,2 & 7,6 \\
\hline \multicolumn{2}{|c|}{$V(S / T \times 100)$} & 23,0 & 17,0 & 78,0 & 41,0 & 50,0 & 81,0 \\
\hline \multicolumn{2}{|c|}{ Carbono orgânico $(\%)$} & 0,6 & 0,3 & 0,2 & - & 一 & - \\
\hline \multicolumn{2}{|c|}{ Umidade $(\%)$} & 0,6 & 0,7 & 1,3 & 3,0 & 5,5 & 3,4 \\
\hline
\end{tabular}


APREGIAÇÃO SOBRE OS RESULTADOS ANALÍTICOS DOS PERFIS ESTUDADOS Duas séries de perfis constituídas cada uma de cinco perfis foram tomadas como exemplo. A Tab. I representa os resultados obtidos para o perfil-tipo dos solos desenvolvidos a partir de material autóctone e a Tab. II representa os resultados para o perfil-tipo dos solos desenvolvidos sobre material alóctone. As duas séries de perfis, que chamaremos de grupos, foram divididas em quatro subgrupos, indicados no quadro a seguir com suas respectivas profundidades.

\begin{tabular}{lcr}
\hline Grupo & Subgrupo & $\begin{array}{c}\text { Profundidade, } \\
\mathrm{em} \mathrm{cm}\end{array}$ \\
\hline Autóctone & 1 & 0 a 30 \\
\cline { 2 - 3 } & 2 & 30 \\
\hline Alóctone & 3 & 0 a 30 \\
\cline { 2 - 3 } & 4 & 30 \\
\hline
\end{tabular}

Tomou-se como referência a profundidade de 0 a $30 \mathrm{~cm}$, uma vez que, usualmente, essa é a profundidade amostrada quando das prospecções geoquímicas regionais em solos. Em geral, os latossolos são profundos, apresentando perfis da ordem de 2,50 m. Quando das prospeç̧ões, amostram-se os horizontes superficiais, freqüentemente o horizonte $A$, exatamente o horizonte eluvial, empobrecido pela ação da erosão e dos fenômenos de lixiviação.

Os parâmetros utilizados para a caracterização dos diversos perfis foram os seguintes: $\mathrm{pH}$, cátions trocáveis $(\mathrm{Ca}, \mathrm{Mg}, \mathrm{Na}, \mathrm{K})$, soma dos cátions trocáveis $(S)$, capacidade total de troca $(T)$, porcentagem de argila e teor em elementos-traços ( $\mathrm{Cu}, \mathrm{Co}, \mathrm{Cr}, \mathrm{Mn}, \mathrm{Pb}$ e $\mathrm{Zn})$.

ANÁLISE ESTATÍSTICA DOS DADOS OBTIDOS As médias foram determinadas para cada grupo objetivando estabelecer a existência de diferenças significativas entre as médias dos diversos parâmetros acima referidos no parágrafo anterior. Compararam-se as médias através de uma análise simples de variança (Wine, 1964). Determinou-se o valor $F$ para cada grupo e tomou-se um valor $F$ conhecido ao nível de $95 \%$ de confiança (veja Tab. III). Obteve-se a variança entre os grupos e a variança dentro de cada grupo. Os valores de $F$ escolhidos indicam uma diferença significativa entre os grupos comparados. Nesse caso, pode-se utilizar o Duncan's multiple range test (Wine, 1964), para determinar exatamente a ocorrência de diferenças significativas entre as médias.

As médias foram colocadas em ordem de valores, mínimo a máximo, conforme a Tab. IV. Assim para os valores de $\mathrm{pH}$ temos $R_{p}$ igual a $0,642,0,676$ e 0,699 para 2, 3 e 4 médias, respectivamente; essas médias aumentam em ordem 4 menor que 3,3 menor que 1 e 1 menor que 2. A diferença entre as médias dos subgrupos 2 e 4 é 1,51, valor maior que 0,699 $(p=4)$. Concluiu-se que existe uma diferença significativa entre as médias dos subgrupos 2 e 4 . A diferença das médias dos subgrupos 1 e 3 é 0,97 , maior que $0,642(p=2)$. Verifica-se, portanto, uma diferença significativa entre essas médias. Todas as médias são assim comparadas e, quando não se verifica uma diferença significativa entre elas, coloca-se um traço sob as mesmas. Para o $\mathrm{pH}$ não ocorre diferença significativa entre as médias dos subgrupos 3 e 4, igualmente dos 1 e 2 . A diferença significativa foi observada entre os subgrupos 1 e $3 ; 1$ e $4 ; 2$ e $3 ; 2$ e 4 .

Concluiu-se, por conseguinte, que, em se tratando do $\mathrm{pH}$, os valores mais baixos são observados para os solos desenvolvidos a partir de material alóctone. Dentro do subgrupo 
Tabela III - Médias, valor F, erro-padrão e faixas de menor significância para alguns parâmetros dos solos da quadrícula de Ibitiara

\begin{tabular}{|c|c|c|c|c|c|c|c|c|c|}
\hline \multirow{2}{*}{ Variável } & \multicolumn{4}{|c|}{ Média } & \multirow[b]{2}{*}{$F$} & \multirow[b]{2}{*}{$S_{\bar{x}}$} & \multicolumn{3}{|c|}{$R_{p}$} \\
\hline & $\bar{X}_{1}$ & $\bar{X}_{2}$ & $\bar{X}_{3}$ & $\bar{X}_{4}$ & & & 2 & 3 & 4 \\
\hline $\mathrm{pH}\left(\mathrm{H}_{2} \mathrm{O}\right)$ & 6,10 & 6,59 & 5,13 & 5,07 & 25,1 & 0,227 & 0,642 & 0,676 & 0,699 \\
\hline$\%$ argila & 30,40 & 34,40 & 16,80 & 27,60 & 7,3 & 2,767 & 7,83 & 8,25 & 8,52 \\
\hline $\mathrm{Ca}($ meq $\%)$ & 8,54 & 11,31 & 1,22 & 1,36 & 23,7 & 1,565 & 4,43 & 4,66 & 4,82 \\
\hline $\mathrm{Mg}(\mathrm{meq} \%)$ & 3,87 & 9,58 & 0,50 & 1,35 & 14,0 & 1,417 & 4,01 & 4,22 & 4,36 \\
\hline $\mathrm{K}($ meq \%) & 0,330 & 0,107 & 0,24 & 0,116 & 5,9 & 0,022 & 0,065 & 0,068 & 0,071 \\
\hline $\mathrm{Na}(\mathrm{meq} \%)$ & 0,212 & 0,868 & 0,035 & 0,063 & 5,9 & 0,104 & 0,295 & 0,301 & 0,321 \\
\hline $\mathrm{S}$ & 12,88 & 17,28 & 1,86 & 2,63 & 21,6 & 1,737 & 4,92 & 5,18 & 5,35 \\
\hline $\mathrm{T}$ & 16,32 & 19,52 & 3,27 & 3,27 & 24,1 & 1,984 & 5,62 & 5,91 & 6,11 \\
\hline $\mathrm{Cu}(\mathrm{ppm})$ & 16,0 & 20,9 & 3,3 & 4,2 & 6,3 & 3,91 & 11,07 & 11,65 & 12,04 \\
\hline $\mathrm{Co}(\mathrm{ppm})$ & 16,5 & 19,9 & 0,98 & 3,0 & 16,8 & 3,05 & 8,63 & 9,09 & 9,39 \\
\hline $\mathrm{Cr}(\mathrm{ppm})$ & 14,5 & 11,5 & 3,1 & 2,6 & 19,0 & 1,83 & 5,18 & 5,45 & 5,64 \\
\hline $\mathrm{Mn}(\mathrm{ppm})$ & 299,0 & 332,0 & 36,0 & 29,0 & 11,7 & 59,8 & 16,9 & 178,0 & 184,0 \\
\hline $\mathrm{Pb}(\mathrm{ppm})$ & 11,1 & 9,5 & 6,3 & 7,2 & 2,59 & 1,28 & - & - & - \\
\hline $\mathrm{Zn}(\mathrm{ppm})$ & 47,7 & 71,1 & 13,7 & 12,6 & 8,3 & 11,8 & 33,42 & 35,19 & 36,37 \\
\hline
\end{tabular}

Tabela IV - Médias anômalas ordenadas. As linhas indicam médias sem diferença significativa

\begin{tabular}{|c|c|c|c|c|}
\hline \multirow{2}{*}{$\begin{array}{l}\text { Variável } \\
\mathrm{pH}\left(\mathrm{H}_{2} \mathrm{O}\right)\end{array}$} & \multicolumn{4}{|c|}{ Média mínima $\rightarrow$ Média máxima } \\
\hline & $\underline{\bar{X}_{4}}$ & $\bar{X}_{3}$ & $\underline{\bar{X}_{1}}$ & $\bar{X}_{2}$ \\
\hline$\%$ argila & $\bar{X}_{3}$ & $\bar{X}_{4}$ & $\bar{X}_{1}$ & $\bar{X}_{2}$ \\
\hline $\mathrm{Ca}$ & $\underline{\bar{X}_{3}}$ & $\bar{X}_{4}$ & $\underline{\bar{X}_{1}}$ & $\bar{X}_{2}$ \\
\hline $\mathrm{Mg}$ & $\underline{\bar{X}_{3}}$ & $\bar{X}_{4}$ & $\bar{X}_{1}$ & $\bar{X}_{2}$ \\
\hline K & $\underline{X}_{2}$ & $\bar{X}_{4}$ & $\bar{X}_{3}$ & $\bar{X}_{1}$ \\
\hline $\mathrm{Na}$ & $\underline{\bar{X}_{3}}$ & $\bar{X}_{4}$ & $\bar{X}_{1}$ & $\bar{X}_{2}$ \\
\hline $\mathrm{S}$ & $\bar{X}_{3}$ & $\bar{X}_{4}$ & $\underline{\bar{X}_{1}}$ & $\bar{X}_{2}$ \\
\hline $\mathrm{T}$ & $\bar{X}_{3}$ & $\bar{X}_{4}$ & $\underline{\bar{X}_{1}}$ & $\bar{X}_{2}$ \\
\hline $\mathrm{Cu}$ & $\underline{\bar{X}_{3}}$ & $\bar{X}_{4}$ & $\underline{\bar{X}_{1}}$ & $\bar{X}_{2}$ \\
\hline Co & $\underline{\bar{X}_{3}}$ & $\bar{X}_{4}$ & $\underline{\bar{X}_{1}}$ & $\bar{X}_{2}$ \\
\hline $\mathrm{Cr}$ & $\underline{\bar{X}_{4}}$ & $\bar{X}_{3}$ & $\underline{\bar{X}_{2}}$ & $\bar{X}_{1}$ \\
\hline $\mathrm{Mn}$ & $\bar{X}_{4}$ & $\bar{X}_{3}$ & $\underline{\bar{X}_{1}}$ & $\bar{X}_{2}$ \\
\hline $\mathrm{Pb}$ & $\underline{\bar{X}_{3}}$ & $\bar{X}_{4}$ & $\bar{X}_{2}$ & $\bar{X}_{1}$ \\
\hline $\mathrm{Zn}$ & $\bar{X}_{4}$ & $\underline{\bar{X}_{3}}$ & $\underline{\bar{X}_{1}}$ & $\bar{X}_{2}$ \\
\hline
\end{tabular}


alóctones verifica-se uma diminuição não significativa dos valores de $\mathrm{pH}$ em profundidade. Dentro do subgrupo autóctones verifica-se um aumento dos valores de $\mathrm{pH}$ que, igualmente, não é significativo.

No caso do $\mathrm{Pb}$, não foi verificada diferença significativa e, para esse parâmetro, não se pode aplicar o Duncan's multiple range test.

Interpretação $\mathrm{O}$ estudo das formações superficiais ou material originário dos solos de uma região como a depressão do Rio Paramirim pode fornecer importantes subsídios para a interpretação dos dados geoquímicos em campanhas de prospecção mineral. Tratando-se de região cujas formações superficiais atinjam espessuras de até 5 metros, a prospecção geoquímica regional poderá ser prejudicada se, de início, não for estudada, convenientemente, a natureza desses materiais que recobrem o substrato geológico e que, muitas vezes, sofrem uma fossilização por meio de carapaças ferruginosas, freqüentemente espessas e que interessam a extensas áreas.

$\mathrm{Na}$ depressão do Rio Paramirim, os solos desenvolvidos a partir de material originário alóctone - latossolos profundos (Camargo e Bennema, 1966) - apresentam características morfológicas e químicas nitidamente diferentes daquelas apresentadas pelos solos desenvolvidos sobre material autóctone (solos podzólicos). Igualmente, diferença significativa seria observada se tivessemos efetuado tratamentos estatísticos dos dados obtidos para os solos evoluídos sobre material alúvio-coluvial.

Dão-se a seguir importantes informações evidenciadas a partir do presente estudo.

1) Ocorrem diferenças significativas entre os dois grupos de solos para a maioria dos parâmetros indicados.

2) Considerando-se a profundidade, tomada como referência para a amostragem, não foi verificada diferença significativa dentro dos dois grupos, alóctones e autóctones.

3) Sabe-se que a retenção de elementos-traços nos solos e sedimentos na fração inferior a 2 mícrons está estreitamente ligada à natureza dos minerais argilosos, à presença de matéria orgânica e de certas complexidades que podem ocorrer entre os cátions metálicos e hidróxidos de ferro, por exemplo. Verificou-se que todos os solos desenvolvidos sobre material autóctone apresentam elevado teor em minerais argilosos do tipo montmorilonita, em oposição aos minerais da família da caolinita presentes nos solos desenvolvidos a partir do material originário alóctone. Os elevados teores em elementos-traços estão sempre ligados aos solos que apresentam argilas de alta capacidade de retenção catiônica, o que foi verificado nos solos desenvolvidos sobre material autóctone. Nos solos desenvolvidos a partir de material alóctone, os teores em elementos-traços são sempre muito baixos, o que pode indicar tratar-se de:

a) sedimentos provenientes de área-fonte estéril;

b) sedimentos antigos (Terciário e/ou Pleistuceno?), fortemente alterados e lixiviados após a sua deposição.

Isso explicaria os baixos valores de $\mathrm{pH}$ e, conseqüentemente, a fraca saturação do complexo absorvente.

CONCLUSÕES Como conclusões gerais para o presente estudo, destacamos alguns pontos de relevância que poderiam ser aplicados aos problemas referentes à prospeç̧ão geoquímica de regiões semelhantes. 
1) Ocorre sempre uma diferença significativa quando comparamos o teor em certos elementos-traços entre os solos derivados de material originário autóctone e daqueles derivados de material originário alóctone.

2) Dentro dos dois grupos, em média, o teor em elementoș traços aumenta não significativamente com a profundidade.

3) A prospecção geoquímica regional deve ser realizada utilizando-se os sedimentos ativos em regiões que apresentem tais características. Os sedimentos ativos representam, provavelmente, os dois tipos de materiais que recobrem o substrato geológico regional a montante da estação amostrada. Observando-se uma anomalia, esta será representativa não do material que recobre o substrato na área de captação da drenagem, mas do material produto da alteração das rochas subjacentes.

4) Nas áreas onde as formações superficiais alóctones atingem espessura considerável, aconselha-se a prospecção por métodos geofísicos.

5) A prospecção geoquímica detalhada pode ser realizada utilizando-se amostras dos horizontes superficiais dos solos; nesse caso, as anomalias serão epigenéticas quando tratar-se de solos alóctones.

\section{BIBLIOGRAFIA}

ANDREA, R. - 1963 - Chuvas na Bahia - M. V. O.P.; DNOCS-CPE, Salvador, Bahia

CAMARGO, M. N. e BENNEMA, J. - 1966 - Delineamento esquemático dos solos do Brasil. Bol. Técnico n. ${ }^{\circ}$ 1, DPEA, Min. da Agricultura. Rio de Janeiro

CAMPBELL, D. F. e MOUTINHO, L. A. - 1965 - Reconhecimento regional através do Geossinclíneo Centro-Leste Brasileiro. D. G. M., DNPM, Notas Prelim. e Estudos n. ${ }^{\circ} 124$. Rio de Janeiro

KEGEL, W. - 1959 - Estudos geológicos na zona central da Bahia. Bol. da DGM-DNPM, n. ${ }^{\circ}$ 198. Rio de Janeiro

MAACK, R. - 1963 - Geologia e geografia física da bacia hidrográfica do rio de Contas no Estado da Bahia. Bol. da Univ. do Paraná, ser. Geogr. Fís. n. ${ }^{\circ}$ 5. Curitiba

OLIVEIRA, J. J. - 1968 - Contribution à l'étude morphologique du piemont de la Chapada Diamantina dans la région de Livramento do Brumado, état de Bahia, Brésil. Tese de doutorado. Univ. de Paris

OLIVEIRA, J. J. - - 1971 - Da necessidade de um estudo preliminar das formações superficiais como apoio para as prospecções geoquímicas. Not. Geomorfológica, n. ${ }^{\circ} 22$, Univ. de Campinas. Campinas, SP

SCHOBBENHAUS, C. - 1967 - Sumário da geologia da quadrícula de Ibitiara, Bahia. Bol. Estudos, n. ${ }^{\circ}$ 1, SUDENE, DRN, DG. Recife.

REVISED STANDARD SOIL COLOR CHARTS, por M. Oyama, H. Takehara. Japão

WINE, L. R. - 1964 - Statistics for Scientists and Engineers. Prentice Hall, Inc. Eng. Cliffs. Nova York

JACKSON, M. L. et al. - 1952 - Weathering sequence of clay-size minerals in soils and sediments: II. Chemical weathering of layer silicates. Proc. Soil Sci. Soc. Am. 16: 3-6. 